\title{
Structure and Microstructure of Y-doped Strontium Titanate Ceramics
}

\author{
Alexander Tkach, * Paula M. Vilarinho, ${ }^{*}$ and Ian M. Reaney** \\ * Department of Ceramics and Glass Engineering, CICECO, University of Aveiro, 3810-193 \\ Aveiro, Portugal \\ ** Department of Engineering Materials, University of Sheffield, Sheffield S1 3JD, UK
}

High dielectric constant important for functional electronic applications have been reported in the $\mathrm{Sr}_{1-1.5 x} \mathrm{Y}_{x} \mathrm{TiO}_{3}$ ceramic system with a maximum value for $\mathrm{x}=0.01$ coincident with the maximum grain size [1]. This observation points to a possible correlation between the dielectric response and the microstructure of these ceramics. A solid solubility limit around $\mathrm{x}=0.04$ was reported recently by $\mathrm{Fu}$ et al., although the second phase was observed by $\mathrm{X}$-ray diffraction only for $\mathrm{x}=0.07$ [2]. Therefore, the structure, microstructure and local composition of $\operatorname{Sr}_{1-1.5 x} \mathrm{Y}_{x} \mathrm{TiO}_{3}$ ceramics $(x=0$ $0.05)$ prepared by conventional mixed oxide method is investigated in this work by transmission electron microscopy (TEM) and scanning electron microscopy (SEM) equipped with energy dispersive spectroscopy facilities. SEM micrographs of $\mathrm{Sr}_{1-1.5 x} \mathrm{Y}_{x} \mathrm{TiO}_{3}$ ceramics sintered at $1500{ }^{\circ} \mathrm{C}$ for $5 \mathrm{~h}$ (Fig. 1(a-d)) reveal dense microstructures with a normal grain size distribution for $x \leq 0.016$, in accordance to their measured density of $\sim 97 \%$. The plot of the average grain size as a function of Y content (inset of Fig. 2) reveals non-monotonous behavior with a maximum of $\sim 40 \mu \mathrm{m}$ for $\mathrm{x} \approx$ 0.01 , in qualitative agreement with the dependence of maximum grain size on $\mathrm{Y}$ content, reported by Burn and Neirman [1]. Considering the $\mathrm{Sr}_{1-1.5 \mathrm{x}} \mathrm{Y}_{\mathrm{x}} \mathrm{TiO}_{3}$ stoichiometry, creation of strontium vacancies $\mathrm{V}_{\mathrm{Sr}}$ is implied. $\mathrm{V}_{\mathrm{Sr}}$ are the most probable defects, controlling sintering mass transport [3], those increase diffusion coefficient and hence grain growth for low Y content. Grain growth decrease for high $\mathrm{Y}$ content should be associated with grain boundary defects. Energy dispersive spectra taken from several grains of $\mathrm{Sr}_{1-1.5 \mathrm{x}} \mathrm{Y}_{\mathrm{x}} \mathrm{TiO}_{3}$ ceramics with $x \leq 0.016$ indicate the incorporation of $\mathrm{Y}$ into the lattice of strontium titanate (ST), showing small but detectable peaks, Fig. 2a. In addition, elemental $\mathrm{x}$-ray mapping shows that $\mathrm{Y}, \mathrm{Sr}$, and $\mathrm{Ti}$ are distributed homogeneously within the grains. On the other hand, energy dispersive spectra observed on $\mathrm{Sr}_{1-1.5 \mathrm{x}} \mathrm{Y}_{\mathrm{x}} \mathrm{TiO}_{3}$ ceramics with $x=0.05$ are of two types, Fig. 2b. The first type, characterized by strong $\mathrm{Sr}$ and weak Y peaks, was observed on larger grains, whereas the second type, characterized by weaker Sr peaks and much stronger Y peaks, was observed on small grains. To visualize the inhomogeneous distribution of the elements and segregation of the second phase, elemental x-ray mapping was conducted on $\mathrm{Sr}_{0.925} \mathrm{Y}_{0.050} \mathrm{TiO}_{3}$ ceramics, Fig. 3(a-d). Segregation of Y (Fig. 3c) to the small grains was observed which were located mainly but not exclusively at the larger grain boundaries (Fig. 3a). The Y rich grains are deficient in Sr (Fig. 3b), but the Ti concentration is homogeneous (Fig. 3d) throughout the ceramic. Segregation is driven by the large difference in the ionic radius between the host $\mathrm{Sr}^{2+}$ and the dopant $\mathrm{Y}^{3+}$, which is also reflected in the restricted solid solubility limit of $<5 \%$ in accordance to Ref. 2 . TEM analysis (Fig. 2(c,d)) reveals that $\mathrm{Sr}_{1-1.5 \mathrm{x}} \mathrm{Y}_{\mathrm{x}} \mathrm{TiO}_{3}$ samples with $\mathrm{x}>0.01$ are not cubic but tetragonal at room temperature as indicated by the appearance of $1 / 2$ \{odd-odd-odd $\}$ reflections in $<110\rangle_{\mathrm{p}}$ zone axis electron diffraction patterns (ZADP). For undoped ST such reflections are only observed below $105 \mathrm{~K}$ and correspond to the improper ferroelastic phase transition due to antiphase tilting of the oxygen octahedra [4]. The intensity of the reflections increases with Y content, implying an increase of the tilting angle and hence transition temperature. Thereby $\mathrm{Y}$ evidently occupies the Sr site of ST and due to the large difference between the ionic sizes of $\mathrm{Sr}^{2+}$ and $\mathrm{Y}^{3+}$ and the creation of $\mathrm{V}_{\mathrm{Sr}}$ strongly affects the tolerance factor and hence the transition peculiar to ST [4]. 
References

[1] I. Burn, S. Neirman, J. Mater. Sci. 17 (1982) 3510.

[2] Q.X. Fu, S.B. Mi, E. Wessel, and F. Tietz, J. Eur. Ceram. Soc., in press.

[3] A. Tkach, P.M. Vilarinho, et al., J. Eur. Ceram. Soc. 25 (2005) 2769.

[4\} A. Tkach, P.M. Vilarinho, A.L. Kholkin, I.M. Reaney, et al., Chem. Mater., in press.

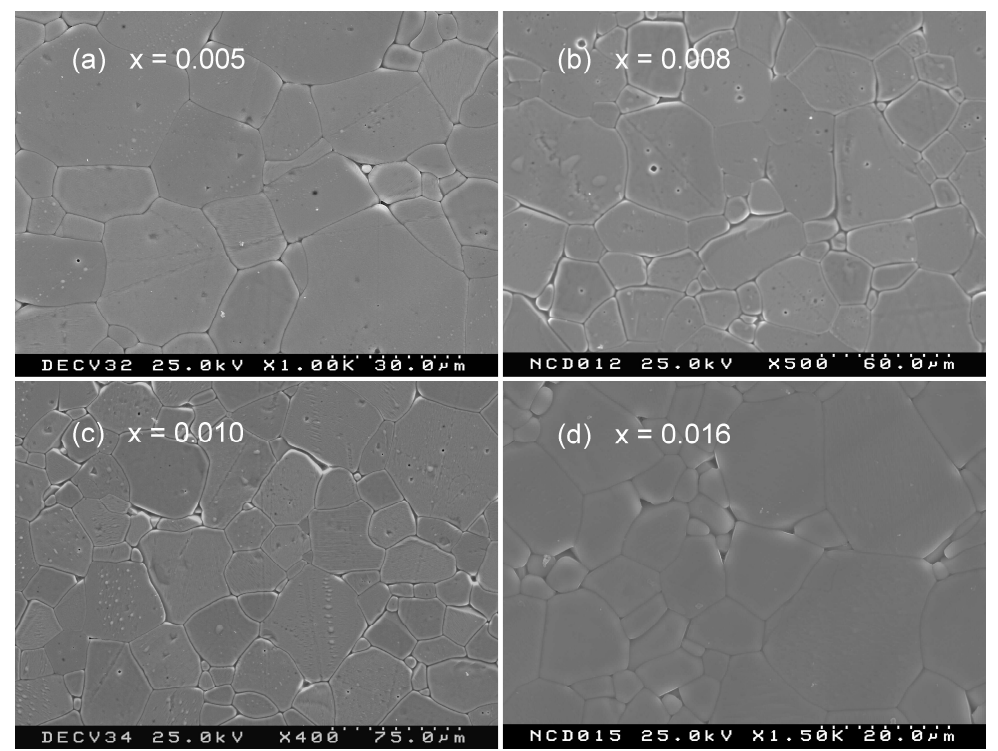

Fig. 1. SEM micrographs of $\mathrm{Sr}_{0.9925} \mathrm{Y}_{0.005} \mathrm{TiO}_{3}(\mathrm{a})$,

$\mathrm{Sr}_{0.988} \mathrm{Y}_{0.008} \mathrm{TiO}_{3}$ (b), $\mathrm{Sr}_{0.985} \mathrm{Y}_{0.010} \mathrm{TiO}_{3}(\mathrm{c})$, and

$\mathrm{Sr}_{0.976} \mathrm{Y}_{0.016} \mathrm{TiO}_{3}(\mathrm{~d})$ ceramics.


Fig. 2. Energy dispersive spectra $(\mathrm{a}, \mathrm{b})$ and $<110>_{\mathrm{p}}$ ZADP $(\mathrm{c}, \mathrm{d})$ of $\mathrm{Sr}_{0.976} \mathrm{Y}_{0.016} \mathrm{TiO}_{3}(\mathrm{a}, \mathrm{c})$ and $\mathrm{Sr}_{0.925} \mathrm{Y}_{0.050} \mathrm{TiO}_{3}(\mathrm{~b}, \mathrm{~d})$ ceramics. Inset shows average grain size deduced from SEM micrographs of $\mathrm{Sr}_{1-1.5 \mathrm{x}} \mathrm{Y}_{\mathrm{x}} \mathrm{TiO}_{3}$ ceramics as a function of $Y$ content $x$.

Fig. 3. SEM micrograph of $\mathrm{Sr}_{0.925} \mathrm{Y}_{0.050} \mathrm{TiO}_{3}$ ceramics (a) and its elemental X-ray mapping for $\mathrm{Sr}(\mathrm{b}) \mathrm{Y}$ (c) and $\mathrm{Ti}(\mathrm{d})$. 